\title{
A CONTRIBUIÇÃO DA ATUAÇÃO COLETIVA DOS TRABALHADORES PARA O APRIMORAMENTO DO ESTADO DEMOCRÁTICO DE DIREITO
}

\author{
Tulio Macedo Rosa e Silva \\ Universidade do Estado do Amazonas - UEA. Avenida Castelo Branco, 504 - Cachoeirinha. Manaus/AM, Brasil. CEP 69050-000. \\ http://lattes.cnpq.br/6808991461851262. https://orcid.org/0000-0001-5004-2637.tuliomasi@hotmail.com
}

RESUMO

O presente artigo analisou se a atuação coletiva dos trabalhadores contribuiu para a evolução dos modelos de Estado desenvolvidos nos últimos séculos. Foram pesquisadas as raízes e as características do Estado liberal, Estado social, Estado de bem-estar social e Estado democrático de direito. Para tanto, não poderia deixar de ser estudada a relação que o constitucionalismo social mantém com tais modelos estatais, bem como os desdobramentos provocados pelas crises de ordem econômica no sistema capitalista no período. Na presente pesquisa foi utilizado o método dialético, o dedutivo, o histórico, bem como a realização de estudo do tipo teórico-aplicado. A pesquisa conseguiu demonstrar que o verdadeiro Estado democrático de direito deve proporcionar proteção aos direitos humanos fundamentais. Nessa linha, o princípio da liberdade sindical, uma das dimensões do princípio da liberdade, constitui núcleo essencial à defesa do Estado democrático de direito. A atuação coletiva dos trabalhadores contribuiu para a substituição do Estado liberal pelo Estado social. Além disso, a atuação coletiva dos trabalhadores também contribuiu para a evolução do Estado social para o modelo de Estado de bem-estar social. Apesar dos ataques e desmobilização a partir dos anos 70 do século 20, as entidades sindicais continuam contribuindo para 0 amadurecimento do Estado democrático de direito.

Palavras-chave: Estado; direitos humanos fundamentais; liberdade sindical.

THE CONTRIBUTION OF THE WORKERS COLLECTIVE ACTION TO IMPROVE THE DEMOCRATIC STATE ABSTRACT

This research analyzes if the workers collective action help the evolution of the state models developed in the last centuries. The roots and characteristics of the liberal state, social state, welfare state and democratic state were investigated. Besides that, it was studied the relationship that social constitutionalism maintains with such state models, as well as the developments caused by the economic crisis in the capitalist system in the period. In this research, it was used the dialectical, deductive and historical methods, as well as a theoretical-applied study. The research was able to demonstrate that the true democratic state must provide protection for fundamental human rights. Along these lines, the principle of freedom of trade union association, as it integrates the principle of freedom, constitutes an essential nucleus for the defense of the democratic state. The workers collective action contributed to the replacement of the liberal state by the social state. In addition, it also contributed to the evolution of the social state towards the welfare state model. Despite the attacks and demobilization since the 1970s, trade union organizations continue to contribute to the democratic state improvement.

Keywords: State; fundamental human rigths; freedom of trade union association. 


\section{CONSIDERAÇÕES INICIAIS}

O conceito e o exercício da liberdade constituem pressupostos do conceito e exercício da democracia, devendo a liberdade ser, portanto, difundida em todas as camadas sociais, ao contrário de estar limitada somente a algumas elites econômicas e políticas, como ocorria no liberalismo originário. Nesse contexto, não se está defendendo apenas a liberdade formal, mas também a liberdade material, que necessita do acréscimo da ideia e da prática da igualdade. Por conta disso, o surgimento da concepção de democracia, uma das marcas da segunda metade do século 19 , concorre com a consolidação da defesa e da promoção do trabalho e do emprego, por intermédio das entidades sindicais de trabalhadores e partidos de base popular (DELGADO; PORTO, 2007).

Nessa medida, o princípio democrático, reconhecido no texto constitucional, representa mais do que um mecanismo ou processo que os cidadãos possuem de eleger seus governantes; na qualidade de princípio normativo, compreendido em seu ângulo político, econômico, social e cultural, atua como estímulo norteador da sociedade. Consiste em um princípio complexo e apresenta várias dimensões. Nessa linha, conforme os componentes que o integram, deve-se salientar a relevância dos direitos fundamentais, por compreenderem um item essencial em seu estabelecimento. Um regime que seja verdadeiramente democrático deve apresentar, em seu núcleo, a concreta e real proteção dos princípios axiológicos da igualdade, liberdade e solidariedade dos direitos humanos. Assim, o princípio da liberdade sindical, enquanto um dos aspectos do princípio da liberdade, integra o núcleo do regime democrático. Se não existe liberdade de associação e, portanto, liberdade sindical, não há democracia. Esse raciocínio pode ser extraído das várias declarações e normas internacionais, como a Declaração Universal dos Direitos do Homem de 1948 e os Pactos Internacionais de Direitos Civis e Políticos e Econômicos, Sociais e Culturais de 1966 (SANTOS, 2006, p. 1.338).

É interessante lembrar, como aponta Oscar Ermida Uriarte, ser consenso entre os juristas que o desenvolvimento da liberdade sindical não é possível sem a preexistência efetiva dos demais direitos humanos e, ainda, não é possível o completo exercício desses direitos humanos sem a vigência da liberdade sindical. De forma sucinta, não existe liberdade sindical sem o exercício dos outros direitos humanos e vice-versa (ERMIDA URIARTE, 1985. p. 24).

Dessa maneira, segue o autor, o direito de liberdade sindical depende dos demais direitos humanos, pois é impossível, na prática, instituir um sindicato realmente livre que possa desenvolver uma atividade sindical autêntica, sem que, ao mesmo tempo, possam ser exercidos esses direitos humanos. Nota-se, portanto, que a liberdade sindical não é autossuficiente, pois requer a existência efetiva de outras liberdades civis e políticas para poder subsistir. As liberdades civis constituem, assim, o fundamento necessário para a liberdade sindical, pois essa não pode se concretizar sem o respeito aos direitos humanos. Logo, se a liberdade sindical depende dos direitos individuais, deve-se enfatizar, também, que ela, ao mesmo tempo, os condiciona (ERMIDA URIARTE, 1985, p. 25).

Nesse contexto, os modelos de Estado que se sucederam ao longo da História revelam a trajetória da preocupação concedida aos direitos humanos fundamentais. Desse modo, a análise da evolução e das principais características desse grupo de direitos não pode ser dis- 
sociada do estudo concomitante sobre a evolução dos modelos assumidos pelo Estado, pois o desenvolvimento de ambos foi simultâneo e apresenta-se entrelaçado.

Nessa linha, a pesquisa analisou se a atuação coletiva dos trabalhadores contribuiu para a evolução dos modelos de Estado desenvolvidos nos últimos séculos. Sendo assim, foram pesquisadas as raízes e as características do Estado liberal, Estado social, Estado de bem-estar social e Estado democrático de direito. Para tanto, não poderia deixar de ser estudada a relação que o constitucionalismo social mantém com tais modelos estatais, bem como os desdobramentos provocados pelas crises de ordem econômica no sistema capitalista no período.

Na presente pesquisa, portanto, foi utilizado, principalmente, o método dialético, por meio da análise de diversas posições doutrinárias relacionadas aos assuntos investigados.

Em decorrência da natureza do problema abordado, foi empregado, também, o método dedutivo, que se destina a demonstrar e justificar os fatos correlatos ao problema mediante a aplicação de recursos lógico-discursivos, calcados nos seguintes critérios: coerência, consistência e não contradição.

Por fim, o método histórico foi utilizado na pesquisa dos modelos de Estado desenvolvidos nos países analisados.

O estudo é do tipo teórico-aplicado, pois é destinado não apenas a descobrir teoria, lei e modelos de explicação dos fatos jurídicos e sociais, mas, também a solucionar problemas de ordem prática.

Sendo assim, os dados obtidos foram relidos a partir de uma perspectiva crítica e não meramente descritiva, objetivando discutir a adequação dos modelos atualmente adotados ao paradigma do Estado democrático de direito e do movimento pós-positivista.

\section{ESTADO E CONSTITUCIONALISMO SOCIAL}

Nos séculos 18 e 19 surgiu e desenvolveu-se o Estado constitucional, representativo ou de Direito na forma de Estado liberal. Sua organização estava ancorada precipuamente na ideia de liberdade e, em razão dela, o poder político deveria ser contido no âmbito interno por conta de sua divisão, e no âmbito externo em virtude da diminuição ao grau mínimo das suas atribuições diante da sociedade (MIRANDA, 2011, p. 13).

Logo, o Estado de direito surge a partir do constitucionalismo e da garantia constitucional de direitos humanos que passam a ser denominados de direitos fundamentais. Assim, Constituição e direitos fundamentais, quando reunidos, impõem limites normativos ao Estado. Os textos constitucionais conquistam dignidade quando asseguram direitos fundamentais a serem exercidos contra o Estado, e o Estado, quando os cumpre, institui tais direitos (PORTO, 2006, p. 52).

Dessa forma, a instauração desse modelo estatal representou a vitória da burguesia, que conseguiu imprimir suas lutas na configuração da ordem jurídica a partir de então vigente: valorização da liberdade contratual, absolutização da propriedade privada, vedação, durante várias décadas, do direito de associação (alegava-se que ela restringia a liberdade individual) e possibilidade do exercício do direito de voto apenas por aqueles que fossem detentores de algum montante de bens ou rendimentos (sufrágio censitário) (MIRANDA, 2011, p. 13). 
Nesse contexto, pode-se identificar os seguintes atributos do Estado liberal de direito: a) sujeição à autoridade da lei, mas essa lei era reconhecida como ato formal proferido pelo Poder Legislativo, integrado por mandatários do povo, todavia, apenas algumas pessoas eram consideradas parte do povo; b) divisão de poderes, que mantenha apartados, de maneira independente e equilibrada, os poderes Legislativo, Executivo e Judiciário; e c) enunciado e garantia dos direitos fundamentais. Essas concepções são mantidas como requisitos básicos do Estado de direito, representando um grande progresso da civilização liberal (SILVA, 2015. p. 114-115.)

É possível notar que a sucessão de fatos que integra o processo histórico-social de reivindicações por liberdade e igualdade delimita as características do Estado. Nessa medida, o Estado liberal pode ser considerado o promotor da representatividade do cidadão, assegurando-Ihe liberdade e paz social. Mesmo assim, esse modelo exerceu influência na economia capitalista, pois os recursos acumulados pelo Poder Público foram relevantes para o desenvolvimento econômico necessário à preservação do sistema social (ANGNES; BUFFON; MORIGI, 2010).

A civilização do período em que é criado esse modelo estatal é caracterizada por ser capitalista em seu modo de funcionamento econômico, liberal e em sua organização jurídico-constitucional, que tinha a burguesia como classe hegemônica e contava com grandes avanços no campo da ciência e do desenvolvimento. O capitalismo vivenciado na época teve suas bases no mercantilismo e propiciou o desenvolvimento da revolução industrial até chegar ao âmbito fordista de produção, o que possibilitou a concentração da riqueza em poucas mãos, concomitantemente à generalização da pobreza entre as pessoas que não tinham propriedades nem capital (GÓMEZ ISAZA, 2006)

As transformações trazidas pela Revolução Industrial do século 19, todavia, provocaram o término da hegemonia burguesa. É interessante mencionar que o processo de acumulação de capital nos países mais ricos, em virtude do desenvolvimento industrial, somado à produção em escala, ao crescimento do desemprego e às lamentáveis condições de trabalho a que estavam expostos os trabalhadores, provocaram o início de uma nova tensão social, agora entre a burguesia e o proletariado, e não mais entre a burguesia e a nobreza, colocando em lados opostos os proprietários dos meios de produção e os donos da força de trabalho (PORTO, 2006).

É importante lembrar que a Primeira Revolução Industrial e as mudanças nos mecanismos de produção encontram-se no início da estruturação dos regimes direcionados para a disciplina da organização sindical. Nessa linha, o começo do processo situa-se na vedação de criação de organizações profissionais, cuja expressão mais típica foi a lei francesa de 1791, denominada Lei Le Chapelier, que proibiu a existência das entidades. A intervenção do Estado moderno na estrutura das relações coletivas de trabalho estabelece o maior ou menor grau de liberdade sindical, dependendo sempre do regime político vigente. As doutrinas econômicas recentes, desde a keynesiana até a do desenvolvimento econômico, acarretam o progressivo intervencionismo estatal no processo social, primeiramente impedindo e, em seguida, incorporando no aparelho burocrático os "corpos sociais intermediários" (ROMITA, 1987, p. 7), como será analisado nos itens seguintes. 
De qualquer forma, estava claro que o modelo de organização estatal instaurado não correspondia mais às necessidades oriundas das transformações pelas quais passava a sociedade. Nesse momento, o Estado passa a ser requisitado cada vez mais a atuar no mercado e nas relações jurídicas desenvolvidas, especialmente as relações de trabalho, em decorrência da deterioração crescente das condições de trabalho.

O proletariado que se formava passa a enxergar no Estado, dominado pela burguesia, um inimigo que deveria ser vencido e eliminado. Essa noção foi desenvolvida nos movimentos proletários da época, que prometiam a distribuição das riquezas e a instituição de uma ordem social em que as pessoas ganhavam conforme seu trabalho e de acordo com suas necessidades (DALLARI, 2003, p. 283-284).

Nesse contexto, é interessante mencionar a atuação da Liga dos Comunistas, união operária internacional classificada como ilegal nos países onde existiam massas operárias, que criou, de forma secreta, um Congresso em Londres em novembro de 1847. Nessa ocasião, Karl Marx e Friedrich Engels ficaram responsáveis pela elaboração de um programa teórico e prático para nortear o movimento comunista. Surge, assim, o Manifesto Comunista, de 1848, que recomendava a união dos operários na luta contra a burguesia e influenciaria a classe proletária, estimulando a corrente socialista que predominaria sobre as demais vertentes consideradas utópicas (DALLARI, 2003, p. 284).

Além do Manifesto Comunista de 1848, cumpre lembrar a criação da Associação Internacional dos Trabalhadores (AIT), em Londres, no ano de 1864, conhecida como Primeira Internacional. A organização é considerada um prolongamento da Liga dos Comunistas, cujo principal objetivo consistia na formação de um canal central de comunicação e de cooperação entre as organizações operárias de vários países (COGGIOLA, 2011).

Todos esses movimentos sociais proporcionaram um contexto que desenhava a necessidade de o Estado legislar a respeito dos direitos dos trabalhadores. A própria Igreja Católica contribuiu para a formação desse contexto a partir da elaboração da encíclica Rerum Novarum pelo Papa Leão XIII em 1891.

Sem outra saída, o Estado começa a reconhecer uma série de direitos ao novo segmento social que se formava. $\mathrm{O}$ ápice desse processo ocorre com a contemplação desses direitos no texto constitucional, fenômeno que ficou conhecido como constitucionalismo social.

Tradicionalmente confere-se à Constituição Mexicana de 1917 a origem formal do constitucionalismo social no século 20. O diploma constitucional é resultado da Revolução Mexicana de 1910-1917, tendo encerrado os 34 anos da ditadura de Porfírio Diaz. Seu texto é anticlerical, agrarista, nacionalista e social, com ampla influência anarcossindicalista. Nessa linha, pela primeira vez foram positivadas normas cuja finalidade era a proteção do trabalho humano e o atendimento das necessidades sociais dos mais necessitados. Foram consagrados direito ao salário mínimo, limitação de jornada de trabalho (oito horas) e ao trabalho da mulher e da criança, permissão de livre-associação em sindicatos e o direito à greve. Em complemento, foram reconhecidos direitos sociais "latu sensu", como o direito à educação (FELICIANO, 2016, p. 552).

Em reação ao sistema capitalista, o texto constitucional mexicano foi o pioneiro a consagrar a desmercantilização do trabalho, proibindo sua equiparação a uma mercadoria qualquer 
que estivesse submetida à lei da oferta e da procura. Ele abriga o princípio da igualdade material de posição jurídica entre empregadores e trabalhadores na celebração do contrato de trabalho, estabelecendo a responsabilidade dos empregadores por acidentes de trabalho e, de uma forma geral, projetou os alicerces para o desenvolvimento do Estado social de direito. Nessa medida, acabou com a legitimidade conferida às práticas de exploração mercantil do trabalho, e, consequentemente, da pessoa humana, que era realizada com fundamento na liberdade de contratar (COMPARATO, 2008, p. 181).

Pouco mais de dois anos depois, entra em vigor a Constituição de Weimar (1919), na Alemanha, considerada o marco do constitucionalismo social do século 20. Nesse contexto, o diploma constitucional realçou a unidade federal e assinalou a mudança do modelo liberal para o modelo social de Estado. Dentre os direitos consagrados podem-se citar: proteção ao trabalho, liberdade de associação para a proteção e progresso das condições de trabalho, necessidade de concessão de tempo livre aos empregados para exercerem direitos cívicos e funções públicas e direito à seguridade social. Além disso, a Alemanha mostrou para o mundo a necessidade de regulamentar no plano internacional a situação jurídica dos trabalhadores, garantindo-Ihes um grupo de direitos mínimos sociais, situação que se concretizou com a criação da OIT, também em 1919, e sua posterior atividade normativa (FELICIANO, 2016, p. 552).

Em complemento, cumpre destacar que as linhas norteadoras do Estado da democracia social, traçadas pela Constituição mexicana em 1917, foram aperfeiçoadas na Alemanha de 1919. Essa estrutura estatal foi retomada em vários países após o período nazi-fascista e a Segunda Guerra Mundial. A democracia social simboliza, de fato, até o final do século 20, a forma mais efetiva de proteger a dignidade humana, ao conjugar aos direitos civis e políticos a proteção garantida pelos direitos econômicos, sociais e culturais, desprezados pelo liberal-capitalismo. Em certa medida, os dois Pactos Internacionais de direitos humanos de 1966 representam o final do processo de institucionalização da democracia social, inaugurado pelas Constituições Mexicana e Alemã do começo do século (COMPARATO, 2008, p. 193).

Cumpre citar, ainda, a Declaração Soviética dos Direitos do Povo Trabalhador e Explorado (17.1.1918) e a Lei Fundamental Soviética (10.7.1918), que não trouxeram um simples projeto de Estado social, mas conceberam um Estado socialista, o "Estado socialista-proletário". Nessa linha, foram instituídas providências radicais, como a eliminação da propriedade privada, ao mesmo tempo em que foram assegurados direitos sociais, como a assistência econômica aos operários e camponeses mais pobres (FELICIANO, 2016, p. 552).

O constitucionalismo social, portanto, simboliza o rompimento com a tradição burguesa de dominação do Estado com o intuito principal de assegurar a liberdade de contratação e a acumulação de riquezas. Esse modelo encontra-se defasado a partir das transformações sociais oriundas dos desdobramentos da Revolução Industrial. O proletariado surge como nova força social que lutará por transformações na organização da sociedade e mostrar-se-á importante elemento para o equilíbrio das forças necessária à manutenção da paz social. Para que esse projeto pudesse ser levado adiante, o exercício da liberdade sindical assumiu grande relevância, pois, em razão dela, os trabalhadores puderam atuar na busca pelas transformações pretendidas.

Assim, a partir do desenvolvimento do constitucionalismo social, é possível verificar que o Estado passa a ser estruturado com fundamento no princípio da igualdade material, supe- 
rando a concepção de igualdade formal, que é alheia à existência de desigualdades no plano fático entre as pessoas. O modelo de Estado que se desenvolve então, será analisado no próximo tópico (FELICIANO, 2013, p. 131-132).

\section{ESTADO SOCIAL, ESTADO DE BEM-ESTAR SOCIAL E TRABALHO}

Para compreender de forma mais profunda o modelo do Estado que surge após a superação do modelo de Estado liberal, cumpre destacar, primeiramente, que o liberalismo, como doutrina política, propiciou uma distinção inconciliável entre a esfera do público e do privado, relacionada às instituições políticas e jurídicas. A função do Estado era reduzida aos casos que não poderiam ser solucionados pela iniciativa particular. Sua atuação, portanto, era restrita à administração da justiça, polícia e exército. A burguesia, que havia pleiteado os direitos de propriedade e liberdade, direitos esses com conteúdo essencialmente econômico, assume os direitos políticos para exercê-los em nome do povo e da nação, realizando a defesa de seus próprios interesses ao invés do interesse coletivo. Dessa maneira, a sociedade concebia o indivíduo como um "ser capaz", suficiente para transformar sua própria realidade e seu entorno social; para que isso pudesse ocorrer o indivíduo dispunha da razão bem como da autonomia de sua vontade, que promoviam uma conduta de otimismo na busca constante de conhecimento (GÓMEZ ISAZA, 2006).

Nessa perspectiva, é importante mencionar que o individualismo, associado ao neutralismo ou abstencionismo típicos do Estado liberal, criou injustiças profundas na sociedade. Dessa forma, as lutas dos movimentos sociais oriundos do século 19 evidenciavam que as liberdades burguesas não eram suficientes para garantir justiça social a toda a população (SILVA, 2015, p. 117). Os questionamentos dos valores do Estado liberal permitiram alterações de diretrizes e conteúdo por volta da metade do século 19. Assim, o Estado começa a oferecer serviços públicos, garantindo direitos vinculados à cidadania, como relações de trabalho, previdência, saneamento, saúde e educação. Logo, diante dessa mudança de papel, o modelo estatal é alterado de Estado liberal para o que ficou conhecido como Estado social (ANGNES; BUFFON; MORIGI, 2010).

Em meio a esse cenário, as primeiras organizações sindicais e políticas no final do século 19 , aliadas ao desenvolvimento dessas políticas sociais dos Estados (primeiramente no campo previdenciário e de acidente do trabalho), são marcas do surgimento dessa nova estrutura estatal. Na esfera político-sindical, as mobilizações trabalhistas e socialistas, desenvolvidas no Reino Unido, França e Alemanha, foram difundidas para outras nações capitalistas já na segunda metade do século 19. Na esfera político-institucional, os ordenamentos jurídicos passaram a prever paulatinamente normas trabalhistas, atribuindo cidadania social e política aos operários enquanto indivíduos e reconhecendo-os como grupo social. Nessa linha, a Conferência de Berlim de 1890, que contou com a participação de 14 países europeus, ao estabelecer um conjunto de normas trabalhistas que passariam a ser cumpridas pelos Estados participantes, representou uma relevante função na formação do modelo estatal que se desenvolvia (DELGADO; PORTO, 2007).

Tradicionalmente, Hegel é identificado como autor elementar para o modelo de Estado social criado. Defende-se, em "Princípios da Filosofia do Direito", que o poder estatal é dotado de uma função de proteção dos pobres. Em outra vertente, Fichte promove a perspectiva 
de um Estado envolvido com as distintas relações da vida, atribuindo um dever de assistência às necessidades essenciais. Posteriormente, Robert von Mohl e Lorenz von Stein trazem elementos relevantes para a construção de uma teoria do Estado social. Ademais, os conflitos sociais ocorridos na segunda metade do século 19 desenvolveram as condições que propiciaram a construção do modelo bismarckiano de seguro social (LOUREIRO, 2007).

Nas décadas iniciais do século 20 alguns elementos contribuíram para a concretização do Estado social, devendo-se destacar dois deles. Primeiramente, o surgimento do socialismo e a constante ameaça que ele representava aos governos capitalistas, especialmente após a Revolução Russa de 1917, aliados à criação dos partidos de cunho popular na Europa ocidental, que apresentavam raízes comunistas, socialistas ou mesmo apenas trabalhistas. Em segundo lugar, a falência do modelo ultraliberal de Estado, realçado pela crise de 1929, que provocou recessão e desemprego em grande parte dos países europeus já no começo da década de 20 e nos EUA a partir de 1929 (DELGADO; PORTO, 2007).

Nos anos seguintes a Primeira Guerra Mundial a concepção de Estado social aparece como modelo contrário ao liberalismo econômico. Nesse período, todavia, foram várias as ideologias desenvolvidas que culminaram na criação do Estado corporativo-fascista ou fascizante e o Estado soviético-marxista, que mantêm diferenças inconfundíveis com o denominado Estado social de direito (MIRANDA, 2011).

Cumpre lembrar que a crise do Estado liberal e seus problemas começam a adquirir contornos nos anos finais de século 19 e tem seu estágio definitivo no período entreguerras. A sociedade encontrará, entretanto, não apenas uma crise econômica, mas uma crise política, que será traduzida com o colapso da democracia liberal. Dos 28 Estados europeus, somente 12 manterão a democracia até o ano de 1938, número reduzido a apenas 5 no ano de 1941 (GÓMEZ ISAZA, 2006).

Dessa forma, é possível identificar três fatores concorrentes para o declínio dos valores liberais: a) surgimento de ideologias antissistemas (o comunismo, e suas derivantes autoritárias, e o fascismo); b) avanço de forças irracionais no campo das construções científicas e filosóficas aptas a atingirem as bases da crença na ordem racional, podendo-se mencionar suas funções na tarefa cognitiva às diretrizes da razão, abstração e ao princípio da causalidade, que se depararam com a teoria da relatividade e as correntes voltadas para a intuição e o instinto; c) funcionamento inadequado do sistema econômico internacional, que objetivava restabelecer o modelo de desenvolvimento capitalista do período pré-guerra (GÓMEZ ISAZA, 2006).

De outro lado, a característica central do modelo de Estado social é identificada na incorporação dos direitos sociais, manutenção das liberdades conquistadas, principalmente as liberdades públicas, e todos os direitos e garantias individuais; ademais, afasta-se o liberalismo econômico, mas é mantido o liberalismo político; do poder estatal é reivindicada uma atuação insubstituível na economia, sem eliminar a iniciativa privada e o mercado (MIRANDA, 2011).

Esse modelo estatal edificado constitui a sequência do Estado liberal, denominado por alguns como sua segunda fase, cuja instituição ocorreu mais por alteração constitucional do que em razão de movimentos revolucionários. Nessa linha, o Estado social de direito, com amparo na soberania nacional desenvolvida no Estado liberal, promove o sufrágio universal que, por sua vez, compreende um instrumento de ampliação de conquistas de mais direitos sociais. Assim, o governo representativo burguês é substituído pela democracia representativa (MIRANDA, 2011). 
Nesse sentido, duas razões podem ser apontadas para que o Estado social de direito seja compreendido como uma segunda etapa do Estado constitucional: a) sem se levar em consideração os movimentos iluministas, jusracionalistas e o liberalismo filosófico, a liberdade do ser humano mantém-se como valor base da vida em sociedade, e a restrição do poder político continua a ser finalidade comum; b) o povo mantém-se como titular do poder político (MIRANDA, 2003-2004).

É importante enfatizar a existência de diferenças entre o Estado social (Sozialstaat) e o Estado de bem-estar social (Welfare State), conhecido como Estado-providência. O primeiro, Estado social origina-se do constitucionalismo social, injetando uma perspectiva de esquerda no texto constitucional. Alguns estudiosos chegam a defender, de forma equivocada, um "Estado quase socialista" ou "Estado socialista parlamentar". Enquanto isso, o Estado de bem-estar social desenvolve suas políticas, no período pós-guerra, a partir do plano de reedificação da Europa (plano Marshall), com a introdução de modelos econômicos de matriz keynesiana em diferentes países. Nesse sentido, o Estado social assumiu diferentes linhas ideológicas e legislativas (por exemplo, a mexicana, a russa e a alemã), à medida que o Estado de bem-estar social possui um tipo cultural exclusivo, essencialmente capitalista e norte-americano, como uma reação ocidental "aos modelos socializantes que vinham do leste" (FELICIANO, 2013, p. 127-128). ${ }^{1}$

Em relação ao Estado social deve-se salientar que sua finalidade principal é a busca da igualdade, garantindo-se a liberdade. Assim, o Estado não está restrito mais a fomentar a igualdade formal, denominada igualdade jurídica. A igualdade almejada é a igualdade material, não apenas perante a lei, mas por meio dela. A igualdade não restringe a liberdade. O objetivo do Estado passa a ser assegurar a igualdade de oportunidades, o que demanda liberdade e justifica a interferência estatal. Esse Estado ampara e fortalece a unidade política material, transformando-se em palco da luta de classes, e assume a posição de mediador, almejando a integração social com fundamento em um mínimo de valores comuns. Não ocorre a eliminação da luta de classes, mas há o surgimento de instrumentos que assegurem que ela não se deslocará para um embate aberto (BERCOVICI, 2013). ${ }^{2}$

Por fim, para resumir as diferenciações entre Estado social e Estado-providência, cumpre transcrever ensinamentos de António José Avelãs Nunes (2013), no sentido de que "enquanto Estado econômico, o Estado social, para além das suas funções de Estado-providência e de Estado de bem-estar, vestiu a pele de Estado-empresário, de Estado prestador de serviços e de Estado redistribuidor do rendimento" (p. 35).

\footnotetext{
Outras expressões são utilizadas para identificar o Estado de bem-estar social: welfare state ou wohlfahrstaat (LOUREIRO, 2007).

2 Em complemento, é importante enfatizar que os modelos constitucionais ocidentais indicam, de forma expressa ou implicitamente, o compromisso com a efetivação do Estado social de direito no momento em que reconhecem um capítulo de direitos econômicos e sociais. As Constituições da República Federal Alemã e da Espanha são exemplos de indicação expressa, qualificando seus respectivos Estados como socais e democráticos de Direito. A concepção de Estado social de direito, entretanto, é incompleta, pois revela um modelo estatal que se inclina a produzir uma situação de bem-estar geral que assegure o desenvolvimento da pessoa humana. Assim, a expressão Estado social de Direito carrega duas ambiguidades: a primeira consiste no fato de o vocábulo social abrigar várias interpretações, pois a visão social do Direito pode ser utilizada por diferentes ideologias, como ocorreu na Alemanha nazista, Itália fascista, Espanha franquista, Portugal salazarista, Reino Unido de Churchill e Attlee, No Brasil, desde a Revolução de 30, sempre existiram Estados sociais. Destaca-se que a ideologia marxista configura uma exceção, pois não confunde o social com o socialista. A segunda consiste no fato de o modelo esconder uma forma de ditadura do grande capital, que encontrou nesse modelo estatal estruturas capazes de desenvolver o Welfare State, imprescindível à sobrevivência do capitalismo (SILVA, 2015, p. 118).
} 
Enquanto isso, as raízes do Estado de bem-estar social são encontradas a partir da análise das políticas sociais do modelo bismarckiano, que evidencia dois atributos essenciais: sua natureza seletiva ou corporativa e a finalidade de harmonizar os trabalhadores industriais, prejudicando a organização trabalhista e fomentando a paz social. Assim, em 1881, o imperador dirigiu-se ao Reichtag em Berlim para afirmar que reprimir as reivindicações dos trabalhadores não melhoraria a situação vivida por eles na indústria, e a paz social seria atingida por meio da instituição do seguro social para os casos de acidente do trabalho e invalidez, assim como para as hipóteses de doença e velhice. Logo, as técnicas de bem-estar que foram desenvolvidas pelo chanceler Otto von Bismarck concederam benefícios para os trabalhadores e para os empregadores. Em razão disso, a Alemanha bismarckiana transformou-se em um modelo para estudar o Welfare State, como um instrumento preventivo utilizado pelas elites cautelosas contra a ampliação do poder do proletariado (FARIA, 2007).

Outro país europeu foi importante na formação desse modelo. No Reino Unido do pós-guerra, as reformas do Welfare State foram arquitetadas por Sir. William Beveridge, um servidor público de inclinação liberal que se empenhava na reestruturação do sistema de seguridade social do país desde a instituição dos primeiros projetos de seguro para os casos de doença e de seguro desemprego em 1911. Esse programa seria estendido futuramente, originando a Seguridade Nacional, que concederia benefícios como pensão por invalidez, aposentadoria e montepio para viúvas (FARIA, 2007).

Nesse contexto, antes do final da Segunda Guerra Mundial, Beveridge começou a reprovar o modelo existente e sugeriu a instituição de um amplo programa de seguridade social. Surgiu, portanto, o Plano Beveridge, que foi concretizado por um conjunto de textos, como o Social Insurance and Allied Services (Relatório Beveridge de 1942) e o Full Employment in a Free Society (1944). Mesmo, todavia, que as alterações propostas tivessem o objetivo de instituir benefícios e serviços que fossem acessíveis a todos os cidadãos, sendo mais inclusivos que o modelo bismarckiano, cumpre ressaltar que uma de suas principais finalidades era a promoção da solidariedade entre os diferentes segmentos sociais do país, evitando-se sua decadência no período do pós-guerra. Assim, sustenta-se que Beveridge acompanhou a linha de Keynes, pois a seguridade social era concebida como um instrumento macroeconômico apto a garantir a estabilidade. Cumpre salientar o destaque concedido por Beveridge às ligações entre emprego e seguridade social, ou seja, entre bem-estar social e trabalho (FARIA, 2007). ${ }^{3}$

\footnotetext{
É interessante mencionar, ainda, que Esping-Andersen sugeriu uma reformulação conceitual e teórica do Welfare State apresentando três regimes distintos de Estado de bem-estar social, quais sejam, o regime liberal, o regime típico e o regime social democrata, os quais coincidem às espécies de políticas sociais e modelos de bem-estar estudados anteriormente por Titmuss. Nessa linha, o regime liberal desenvolveu-se nos Estados Unidos da América, Austrália e Canadá. Esse regime é caracterizado por benefícios governamentais modestos e incentivo ao consumo, garantindo apenas um mínimo de bens necessário ao bem-estar de todos. O segundo regime foi típico nos países como Áustria, França, Alemanha e Itália. Conhecido também como modelo corporativista de Welfare State, esse regime foi caracterizado pelo Estado responsável por atuar no mercado como provedor de bem-estar. A garantia de direitos sociais sempre foi contestada, pois o que predominou foi a preservação de status diferenciados à população. 0 terceiro regime é típico dos países escandinavos, onde os princípios da universalidade e a desmercantilização dos direitos sociais contemplou os mais necessitados e também a nova classe média. Em vez de tolerar o dualismo existente entre Estado e mercado, entre trabalhadores e classe média, a sociodemocracia perseguiu o Welfare State, que promoveu a igualdade a níveis mais altos e não apenas a igualdade a um mínimo de bens. (ESPING-ANDERSEN, 1998. p. 27).
} 
Deve-se destacar, ainda, que não é apenas a simples previsão constitucional de dispositivos reconhecendo direitos econômicos, sociais e culturais que transforma um país em aderente ao modelo do Estado social. Para que isso se concretize é necessário que o Estado institua políticas públicas que sejam capazes de assegurar o acesso a esses direitos prestacionais. Por conta dessa situação o Estado de bem-estar social foi estruturado de fato após as políticas públicas, que tiveram início nos anos 1930, posteriormente à Grande Depressão (principalmente com o New Deal de Franklin D. Roosevelt). Nessa medida, o início do constitucionalismo social retratou somente a fase de experimentação do Estado de bem-estar social, que foi consolidado no período do desenvolvimento da política do New Deal. ${ }^{4}$

Em complemento, existe uma relação de causalidade entre o constitucionalismo social e o Estado-providência, fato que pode ser identificado pelas próprias políticas sociais consolidadas pelo New Deal (salário mínimo, previdência social, redução da jornada de trabalho, garantias sociais para grupos vulneráveis). Independente das políticas econômicas adotadas, é evidente que as Constituições, ao reconhecerem direitos econômicos e sociais, apontam no sentido de prever uma finalidade e um certo ideal de mundo, caracterizados pela proteção da pessoa humana em seu aspecto social de existência. Ato contínuo, chega-se ao período de expansão no Pós-Segunda Guerra com o Plano Marshall de 1947 e a estruturação do modelo escandinavo (FELICIANO, 2013, p. 134).

Dando sequência à evolução do modelo de Estado, foi desenvolvida, após a Segunda Guerra Mundial, a concepção do Estado como social e democrático de direito, compreendendo um princípio constitucional reconhecido para estruturar a ordem política contemporânea do capitalismo (GÓMEZ ISAZA, 2006).

Nesse sentido, podem-se resumir os atributos desse Estado, que passou a ser conhecido como Estado democrático de direito (ou apenas Estado de direito): liberdade e direitos sociais, poder público prestador de serviços e interventor na economia, sob diretrizes e graus variáveis, mercado condicionado e regulado, manutenção da separação de poderes (apesar de diferente em vários aspectos da separação delineada no século 19) (MIRANDA, 2011).

Nessa linha, a vinculação da socialidade com democraticidade é evidente: uma democracia verdadeira existe somente quando todos possuem iguais oportunidades de participar no governo da polis. Isso porque uma democracia não pode ser estruturada com fome, miséria, analfabetismo e exclusão. Assim, a democracia apenas constitui um "procedimento justo

\footnotetext{
${ }^{4}$ No caso do ordenamento jurídico brasileiro, não há dúvidas de que a ordem constitucional reconhece um Estado social, posto que o artigo 10 da Constituição da República contempla apenas as expressões Estado democrático e Estado de direito. Esse posicionamento sustenta-se em razão de o texto constitucional pátrio abranger as quatro ordens de concretização constitucional vinculadas ao princípio da democracia econômica e social (constituição econômica, constituição do trabalho, constituição social, e constituição cultural). Ademais, a justiça social é eleita como fundamento da ordem econômica e financeira (artigo 170) e como finalidade da ordem social (artigo 193). Logo, constitui uma escolha ideológica que influencia a interpretação de todo o direito infraconstitucional. Deve-se, todavia, registrar que esse não constitui um caminho eleito pelos magistrados ou juristas. Essa escolha foi realizada pela Assembleia Nacional Constituinte em 1988 por meio do exercício do poder constituinte originário (FELICIANO, 2013, p. 132-134).

${ }^{5}$ Quanto à instituição do Estado de bem-estar social no Brasil, autores como Cláudia Angnes, Marciano Buffon e Valdir José Morigi entendem que não houve sua efetivação, mas apenas a tutela de interesses de uma minoria em completo desacordo com os interesses sociais que deveriam ser protegidos pelo Poder Público, pois os países que adotaram esse modelo estatal conseguiram diminuir as desigualdades sociais (ANGNES; BUFFON; MORIGI, 2010).
} 
de participação política se existir uma justiça distributiva no plano dos bens sociais". A juridicidade, a sociabilidade e a democracia são construídas, assim, a partir de um alicerce jusfundamental intransponível, que tem início nos direitos fundamentais do ser humano e termina nos direitos sociais (CANOTILHO, 2010).

Posteriormente, ocorre uma redução do modelo de Estado-providência com a prática de políticas neoliberais nos anos de 1970 e 1980, sob os governos de Margaret Tatcher (Reino Unido), Ronald W. Reagan (EUA) e Helmut Kohl (Alemanha).

O Estado social de direito, portanto, apresenta-se como um modelo estatal voltado a garantir a igualdade material dos cidadãos. O constitucionalismo social é sua marca principal, pois, por meio dele, são assegurados os direitos necessários à igualdade almejada. O Estadoprovidência, por sua vez, apresenta-se como um conjunto de medidas adotadas pelo Estado para garantir a sobrevivência do capitalismo diante de suas crises.

O modelo das iniciativas inerentes ao Estado de bem-estar social, entretanto, começa a enfrentar ataques, que se tornaram mais intensos a partir da crise econômica de 1973/1974 por conta do primeiro choque do petróleo, agravada em 1978/1979 pelo segundo choque do petróleo. Nesse período, críticas de ordem ultraliberal são intensificadas em oposição ao modelo de Estado então praticado (DELGADO; PORTO, 2007).

A decadência desse modelo estatal começa, assim, na década de 70 do século 20 que finaliza o período de 30 anos de ouro do Ocidente no referido século. De forma sucinta, as principais causas para esse declínio são: o endividamento excessivo dos países, que não conseguem mais atender às demandas sociais, o paternalismo exagerado e a convicção de que os recursos públicos são findáveis (TORRES, 2009, p. 162-163).

Nessa linha, a inviabilidade do modelo estatal construído passou a ser defendida sob vários fundamentos, que serão, a seguir, expostos. Sob o ponto de vista dos recursos financeiros, a concorrência entre as economias colabora para ampliar a crise fiscal do Estado ao restringir recursos passíveis de mobilização que, por sua vez, contribuem para a prática de procedimentos de concorrência fiscal que afronta a sustentabilidade do Estado (LOUREIRO, 2007). Essa crise da ordem econômica do capitalismo monopolístico desenvolveu um grande déficit fiscal insustentável pelos países industrializados. Ademais, deve-se registrar a elevação da instabilidade monetária, a estagnação econômica combinada com alta taxa de inflação, a deterioração massiva de alguns setores industriais tradicionais (como a indústria pesada, construção naval, mineração) e o aumento do desemprego entre mulheres e jovens. A redistribuição de recursos de toda a sorte e as disputas que surgem por conta dessa redistribuição na esfera internacional, fazem com que os Estados percam protagonismo em benefício de agentes não estatais (GÓMEZ ISAZA, 2006).

$\mathrm{Na}$ área social foram ampliadas as expressões de mal-estar e de protestos contra situações que eram aceitas sem grande questionamento até então; nessa linha, a discriminação da mulher e a exploração ilimitada de recursos naturais são exemplos dessa realidade (GÓMEZ ISAZA, 2006). Os ataques ao emprego e à proteção social diante de um conjunto de práticas, por exemplo, o dumping social, bem como o desmonte de empresas para serem estruturadas em locais com menor rede de proteção laboral e ambiental, também constituem marcas desse período (LOUREIRO, 2007). 
É interessante observar que os ataques à estrutura do contrato de trabalho sempre foram constantes nos discursos dos oposicionistas à manutenção do Estado-providência. As taxas de trabalhadores empregados nos países onde esse modelo estatal mais se desenvolveu, entretanto, são muito maiores quando comparadas às taxas da população que trabalha como autônoma ou que desempenha trabalho não remunerado (OIT, 2006, p. 80-88). A título de exemplo, pode ser citado o caso da Dinamarca, que, no ano de 2002 , ostentava $91,2 \%$ de sua população economicamente ativa como trabalhadores empregados, enquanto apenas $8,1 \%$ trabalhavam como trabalhadores autônomos. Ao contrário, o Camboja, no ano de 2001, possuía apenas $16,2 \%$ da sua população economicamente ativa como empregados, enquanto $40,9 \%$ trabalhavam por conta própria e $42,8 \%$ da população exerciam trabalho familiar não remunerado. É evidente, portanto, que o contrato de trabalho constitui importante fator para a construção de economias bem-estruturadas e para a disseminação de bem-estar social, garantindo renda e dignidade à população. Ao contrário do que é falsamente divulgado por alguns, a desconstrução das proteções inerentes ao contrato de emprego não gera maior renda tampouco desenvolvimento para o país.

Em pesquisa mais recente, com base em dados de 2016, divulgada pela Organização para a Cooperação e Desenvolvimento Econômico (Ocde), foi constatado que metade dos trabalhadores da Colômbia são autônomos. Em contrapartida, no Japão, 10,6\% da força de trabalho é composta por autônomos e nos Estados Unidos da América esse percentual é de 6,4\%. Já o Brasil, de acordo com a Ocde, é o terceiro país em número de trabalhadores autônomos, que representam $32,9 \%$ de sua força de trabalho, e o quarto país em quantidade de trabalhadores que vivem abaixo da linha de pobreza, totalizando $15,9 \%$ de sua força de trabalho. ${ }^{6}$

Em complemento, é grande o impacto que as novas tecnologias da comunicação provocam, reduzindo as distâncias. A internacionalização das finanças, da produção e do comércio atingem escala mundial. Deve-se lembrar, ainda, que a queda do crescimento demográfico, combinada com o aumento da expectativa de vida, está levando ao crescente envelhecimento da população. Essa população é menos produtiva e necessita de maiores cuidados sociais (GÓMEZ ISAZA, 2006). Somada à elevação da expectativa de vida de forma consistente, a saída precoce do mercado de trabalho produz maior tempo de duração dos benefícios pagos pela previdência social. Não fosse isso suficiente, é importante destacar que todos os direitos, sejam civis e políticos, ou econômicos, sociais e culturais, implicam custos para serem efetivados. Assim, em um ambiente de crise financeira do Estado, a ampliação de despesas leva a procedimentos de racionalização de recursos, o que não impede, muitas vezes, o racionamento deles (LOUREIRO, 2007).

Nessa medida, o Estado de bem-estar social transformou-se em um modelo estatal defasado que precisava ser superado, pois já não reunia condições de lidar com as novas dificuldades trazidas pela economia capitalista globalizada (DELGADO; PORTO, 2007).

Mesmo, todavia, após todos esses ataques sofridos e a construção de discursos de desvalorização, o Estado de bem-estar social conseguiu sobreviver nos principais países euro-

15 PAÍSES com mais trabalhadores autônomos. Forbes, 4 jul. 2008. Disponível em: http://forbes.uol.com.br/carreira/2018/07/15-paises-com-mais-trabalhadores-autonomos/. Acesso em: 11 fev. 2020. 
peus, mantendo suas estruturas principais. A título de exemplo, os países nórdicos, Alemanha, França, Países Baixos e mesmo o Reino Unido, mantiveram o padrão civilizatório construído durante o desenvolvimento do modelo de bem-estar social (DELGADO; PORTO, 2007). ${ }^{7}$

A sobrevivência das principais estruturas mantenedoras do Estado-providência, mesmo diante de todos os ataques sofridos, encontra algumas explicações. A primeira delas consiste no fato de a sobrevivência do capitalismo ser dependente da atuação do Estado. Com maior ou menor participação na economia, o funcionamento do aparato estatal é imprescindível para que o capitalismo prossiga. A última crise econômica de 2008, cujos desdobramentos ainda são sentidos, mostrou bem essa dependência. Além disso, as estruturas de apoio ao trabalhador, criadas ao longo do desenvolvimento desse modelo estatal, mostram que não se pode descartar a participação dos trabalhadores na economia, pois constituem elemento importante para o prosseguimento do sistema. Assim, sendo a busca pela igualdade material um dos objetivos primordiais tanto do Estado social quanto do Estado-providência, deve-se ponderar que a luta pela sua concretização ainda não foi abandonada.

As três décadas seguintes a 1945 propiciaram, principalmente nos EUA e Europa, taxas de crescimento econômico crescentes combinadas com níveis de desemprego considerados aceitáveis, sem as ameaças dos índices de inflação. Esses dados, somados às políticas de matriz keynesianas, permitiram a disseminação da ideia de que a ciência econômica havia encontrado o remédio para as distorções que Keynes conferia ao capitalismo (possibilidade de desemprego involuntário e desigualdades intensas). A "obsolência dos ciclos econômicos" chegou a ser defendida, ao mesmo tempo em que se comemorou a existência de um capitalismo sem crises ou capitalismo post-cíclico (NUNES, 2012, p. 19).

As incoerências e obstáculos do modelo de Estado liberal, entretanto, não foram completamente vencidos no modelo de Estado social. Não fosse isso suficiente, recursos materiais necessários ao cumprimento das funções do Estado começaram a tornar-se escassos em virtude da crescente demanda social. Verifica-se, então, um abalo nas orientações ideológicas, o que acarreta a desintegração dos fundamentos do Estado social, instituindo menores garantias aos direitos sociais típicos desse modelo (ANGNES; BUFFON; MORIGI, 2010).

Com a crise do Estado social, é desenvolvida uma perspectiva mais conservadora do Estado amparada em três fundamentos: a) a ampliação dos gastos públicos provoca desequilíbrio orçamentário, o que acarreta déficits públicos, dificultando a atividade produtiva e gerando desemprego e inflação; b) o desenvolvimento dos programas sociais representa interferência do poder estatal na vida social, diminuindo a democracia e prestigiando iniciativas voltadas ao totalitarismo ou autoritarismo; c) os programas sociais incentivariam a inércia das pessoas, pois acabariam com os riscos, o que atingiria a ética do trabalho e, consequen-

\footnotetext{
Os autores defendem o modelo de Estado de bem-estar social sustentando ser apropriado para atender às particularidades dos países latino-americanos, principalmente o Brasil, pois reúne as condições necessárias para adotar as medidas imprescindíveis à manutenção do crescimento econômico e o simultâneo desenvolvimento da justiça social. O caráter intervencionista dessa modalidade estatal invoca a prática de políticas públicas essenciais ao crescimento econômico, como a administração racional do câmbio, do crédito e da política de juros, bem como o estabelecimento de investimento público e privado na economia, dentre outras. Ao mesmo tempo, esse caráter intervencionista realiza políticas sociais que garantam a distribuição de renda, como a elevação do salário-mínimo, medidas eficazes de aumento de renda, ampliação dos níveis de emprego e aumento das oportunidades no sistema econômico, social e cultural.
} 
temente, prejudicaria o mercado, um vez que a competitividade da mão de obra estaria comprometida (ANGNES; BUFFON; MORIGI, 2010).

Diante desse quadro, foi natural o surgimento de novas orientações completamente contrárias àquelas que indicavam o modelo agora em crise. Nesse contexto, emerge a concepção neoliberal de Estado, que tem o intuito de regular as relações econômicas e sociais.

Os neoliberais utilizaram as dificuldades enfrentadas pelos Estados nesse período para, numa "operação relâmpago de propaganda ideológica sem paralelo", atribuí-las a Keynes e às suas políticas. Era o início da "contrarrevolução monetarista" traduzida no retorno a concepções sobre a economia e sobre a função desempenhada pelo Estado que se acreditava abandonadas. Reformulando a concepção de Estado mínimo, o Estado capitalista utilizou novos instrumentos para efetuar seu papel. Dessa forma, incentivou a privatização do setor público empresarial; a destruição das iniciativas do Estado-providência; construiu condições para a hegemonia do capital financeiro e para a plena liberdade de circulação de capitais; incentivou a "liberdade da 'indústria' dos 'produtos' financeiros, criados em profusão, sem qualquer relação com a economia real"; e acreditou na independência dos bancos centrais, na desregulamentação dos mercados e na diminuição dos direitos trabalhistas como medida de ampliar a competitividade (NUNES, 2012, p. 20).

O neoliberalismo criou, no entanto, mais problemas que soluções. Sua concepção de poder é negativa e é orientada no intuito de dissolver o Estado nacional, fragilizando os laços de soberania e, simultaneamente, ensinando uma equivocada despolitização da sociedade. Seu percurso é silencioso, desvinculando-se de qualquer referência de valores. Mesmo assim, é evidente que possui o intento de conservar o status quo de dominação (BONAVIDES, 2016, p. 585).

A crise financeira, e depois a econômica, que ocorreu a partir do ano de 2008, mostra a necessidade de um "retorno ao Estado". O Estado reassume sua função central na liderança da economia que havia sido perdida no término do século 20. Não fosse isso suficiente, ele readquire sua posição fundamental na evolução das sociedades. Esse perfil neoliberal, que não se afasta do triunfo do liberalismo econômico e político, constitui apenas uma lacuna que deve ser encerrada, posto que o Estado recuperou sua "glória passada" (CHEVALLIER, 2009, p. 279).

É impossível negar que o capitalismo financeiro transnacional tenha se transformado em uma peça relevante no cenário político, econômico e social. Embora esteja vinculado à crise provocada pelo uso de ativos tóxicos, em setembro de 2008, esse capitalismo tem conquistado expressivo poder, enquanto as políticas públicas encontram-se destituídas de sucesso contra a força dos mercados (MIRANDA, 2011).

Sendo assim, alguns projetos de resgate da economia foram estruturados para evitar o colapso do sistema financeiro. Basicamente três mecanismos de ação foram adotados: garantia dos empréstimos no mercado interbancário, podendo ser desbloqueadas somente para fins subsidiários; compra dos "ativos tóxicos" dos bancos; e a entrada do Estado no capital dos bancos ameaçados. Todos esses planos mostraram-se insuficientes para solucionar as dificuldades do setor bancário. Assim, logo em seguida, os Estados de todo o planeta tiveram de instituir planos de incentivos que atingiram a marca de 2.800 bilhões de dólares em dois anos (equivalente a $5 \%$ do PIB mundial), com o intuito de eliminar os efeitos depressivos da crise. Os recursos foram utilizados para financiar grandes obras e projetos de infraestrutura, 
ajudar as empresas e os setores industriais mais prejudicados (automobilístico, por exemplo) e tomar iniciativas de suporte ao consumo e às vítimas de desemprego. Tudo isso mostra o retorno da presença do Estado na economia (CHEVALLIER, 2009, p. 282).

O apogeu da crise que ocorreu nos anos de 2010 e 2011 conta, ainda, com o aumento do endividamento das famílias e do endividamento público dos EUA e de vários países europeus. Diante desse quadro, indaga-se se as saídas apontadas pelo Fundo Monetário Internacional e pelo Banco Central Europeu, baseadas nos cortes orçamentários, elevação dos impostos, flexibilização dos contratos de trabalho, elevação das taxas e tarifas de serviços públicos, que incidem na economia, trarão a solução para a crise ou provocarão seu prolongamento por mais tempo (MIRANDA, 2011).

Apesar de todo esse quadro, somente alguns poucos radicais neoliberais defendem o fim integral do Estado social. Isso porque esse modelo estatal mostrou-se elemento apto a fomentar a pacificação, integração e estabelecimento do crescimento econômico, posto que sua eliminação provocaria aumento da instabilidade e conflituosidade social. Além disso, ele está arraigado na consciência jurídica das sociedades que foram contempladas com seu desenvolvimento. Logo, não se imagina a viabilidade de o eleitorado apoiar a supressão desse modelo estatal (MIRANDA, 2011).

\section{ESTADO E LIBERDADE SINDICAL}

A liberdade sindical surge como fruto das lutas oriundas do movimento sindical. É grande atualmente, entretanto, o desinteresse pelos movimentos sindicais, e sua aparente decadência é buscada no plano da economia capitalista contemporânea. Nesse sentido, são apontados o surgimento de novas tecnologias, novas formas de organização do trabalho, queda da ocupação na indústria e aumento dos postos de trabalho no setor de serviços, desemprego, ampliação do setor informal, dentre outros, como responsáveis por levar o sindicalismo a uma decadência irreversível (BOITO JUNIOR, 2003).

Os últimos acontecimentos, todavia, no cenário internacional, como o fluxo crescente de refugiados em direção à Europa, e no plano nacional, como o fortalecimento do discurso sobre a necessidade de realização de reformas na legislação trabalhista e previdenciária, mostram o contrário. Nessa medida, é impossível não levar em consideração a força e a relevância que o movimento sindical desempenhou e ainda pode desempenhar para a garantia das estruturas sociais necessárias à concretização das diretrizes democráticas e de proteção dos direitos humanos. O movimento sindical, como resultado da organização espontânea da sociedade contrária à exploração do homem, possui, em seu gene, a irresignação diante das desigualdades sociais provocadas, no fundo, pela ganância humana ilimitada.

Dessa forma, para proteger a parte hipossuficiente da relação de poder que caracteriza a relação de trabalho, é imprescindível a reconstituição da igualdade ou, pelo menos, diminuir ou reparar a desigualdade existente. De maneira contrária ao verificado nas relações reguladas pelo direito civil, cujo pressuposto é a igualdade das partes, e, portanto, há uma abstenção de interferência nessas relações, no direito do trabalho a desigualdade entre as partes é evidente, fato que justifica sua intervenção para retificá-la (ERMIDA URIARTE, 2013). 
Logo, o direito do trabalho corrige a desigualdade de forma autônoma e heterônoma. No curso da revolução industrial surgiu primeiro a autonomia. Os próprios trabalhadores reuniam-se, por intermédio dos sindicatos, e reivindicavam, inclusive utilizando o mecanismo da greve, melhores condições de trabalho via convenção coletiva. Simultaneamente, o poder estatal, por meio de leis mais protetoras, inspeção de trabalho e justiça especializada na área trabalhista dotada de procedimento próprio, constrói um conjunto de intervenções com o objetivo de proteger e promover a igualdade (ERMIDA URIARTE, 2013).

A ideologia liberal, influenciada ainda pelas experiências da luta contra o Antigo Regime, entretanto, concebia a associação privada como uma ameaça ao interesse coletivo, pois a reunião de pessoas em razão de um interesse de classe possibilitaria a intervenção desses grupos na atividade do Estado e, em último caso, correr-se-ia o risco de criar um segmento social dotado de privilégios corporativistas (EBERT, 2007, p. 21).

Essa não foi, porém, a concepção que prevaleceu nos textos normativos internacionais e constitucionais relacionados à liberdade de associação e à liberdade sindical.

Cumpre ressaltar que o princípio genérico da liberdade de associação abrange o conteúdo relacionado à organização interna dos entes associativos e as relações mantidas com o Poder Público (DELGADO, 2017, p. 67).

Qual seria, no entanto, o papel das entidades sindicais e da liberdade sindical quanto às relações mantidas com o Estado? Num primeiro momento a defesa da liberdade sindical parece ser uma ideia contraditória, pois significa maior pressão junto ao Poder Público, uma vez que propicia uma política de consumo, enquanto o crescimento econômico exige um comportamento de poupança, voltado para o sustento do crescimento. Esse raciocínio é repetido diversas vezes por economistas amparados nas lições de Keynes, que defende que os assalariados possuem tendência para o consumo, enquanto os empresários estão voltados para o investimento. $\mathrm{O}$ crescimento econômico, todavia, não é parâmetro para o desenvolvimento, pois esse último, apesar de necessitar de algum nível de crescimento, é construído especialmente por alterações na estrutura da sociedade, que abrange vários fatores de natureza não econômica. Octavio Bueno Magano (1993) lembra os ensinamentos de Charles Kindleberger, que afirma que o crescimento econômico corresponde a maior produto e o desenvolvimento econômico necessita de maior produto e alterações na conjuntura técnica e institucional da produção. Assim, o desenvolvimento corresponde a alterações na estrutura da produção e na repartição de insumos (MAGANO, 1993, p. 47).

O sindicato reúne condições de criar função relevante no desenvolvimento econômico, incentivando a produtividade de algumas empresas que, sem as pressões por ele exercida, inclinar-se-iam apenas a manter a produção, sem auxiliar na transferência de maior renda aos trabalhadores, ao mesmo tempo em que constitui organismo apto na defesa dos interesses desses trabalhadores (MAGANO, 1993, p. 48).

Além disso, como aponta José Rodrigo Rodriguez (2003), pode ser que as entidades sindicais estejam lutando por um mundo em decadência; pode ser que elas sejam sucedidas por conselhos no interior das empresas que solucionem todos seus problemas; o trabalho subordinado pode desaparecer ao longo do tempo, sendo trocado por trabalhadores temporários e profissionais especializados em alguns serviços. Mesmo assim, a classe trabalhadora não 
pode fugir da discussão e muito menos deixar de participar e influenciar na construção de um novo sistema econômico (RODRIGUEZ, 2003, p. 212).

Dessa forma, da mesma maneira que a experiência dos anos 50, 60 e 70 do século 20 evidenciou a função integradora que a concretização dos direitos sociais pode desempenhar, agora apenas o Estado social é capaz de solucionar os novos desafios que se projetam, por exemplo, a proteção dos milhões de emigrantes. Ademais, somente esse modelo de Estado consegue assegurar a conservação do meio ambiente, por intermédio de uma política de desenvolvimento sustentável (MIRANDA, 2003-2004).

Logo, sempre haverá espaço para que as entidades sindicais atuem na busca por ampliar a rede de proteção daqueles que dependem de sua força de trabalho para sobreviver, incluindo, nesse grupo, não apenas os empregados, mas também aqueles que não possuem contratos de emprego, como os trabalhadores vinculados às plataformas digitais. A união de esforços fomenta reflexões e a análise de diferentes perspectivas para progredir sempre no estabelecimento de melhores de condições de trabalho e de vida.

\section{CONSIDERAÇÕES FINAIS}

O presente estudo conseguiu demonstrar que o verdadeiro Estado democrático de direito deve proporcionar proteção aos direitos humanos fundamentais, assegurando, assim, a garantia do respeito aos princípios da igualdade, liberdade e solidariedade.

Nessa medida, o princípio da liberdade sindical, como uma das dimensões do princípio da liberdade, constitui núcleo essencial à defesa do Estado democrático de direito. Logo, a atuação coletiva dos trabalhadores contribuiu para a substituição do Estado liberal pelo Estado social. Para que isso fosse concretizado, o constitucionalismo social, inaugurado formalmente pela Constituição mexicana de 1917, teve grande participação nas conquistas obtidas pela atuação coletiva dos trabalhadores.

Em seguida, ao lado de várias medidas estatais instituídas em diferentes países e governos, a atuação coletiva dos trabalhadores contribuiu para a evolução do Estado social para o modelo de Estado de bem-estar social.

A organização e atuação coletiva dos trabalhadores, todavia, foram vítimas de ataques e de desmobilização a partir dos anos 70 do século 20, em virtude das sucessivas crises econômicas experimentadas pelo sistema capitalista e da efetivação de medidas neoliberais pelos governos.

Mesmo assim, é impossível negar a contribuição que as entidades sindicais proporcionaram e ainda proporcionam para que o amadurecimento do Estado democrático de direito seja efetivado.

Dessa forma, as entidades sindicais demonstram papel fundamental no desenvolvimento econômico, pois, além de exercerem suas funções básicas vinculadas à representação dos trabalhadores e negociação de melhores condições de trabalho, fomentam o aumento da produção das empresas ao proporcionarem a ampliação da renda dos trabalhadores. Isso porque, ao final da cadeia produtiva, essa renda será revertida para o aumento do consumo das famílias dos próprios trabalhadores, movimentando toda a economia. 


\section{Humanos e \\ Democracia}

Pelas razões apontadas, é imprescindível a defesa da manutenção do Estado democrático de direito. Mesmo com todos os ataques sofridos e todas as fragilidades expostas, não foi criado um outro modelo estatal capaz de conjugar a necessária manutenção do capitalismo e a busca pelo contínuo estabelecimento dos direitos humanos fundamentais. Para tanto, as entidades sindicais continuam a desenvolver o protagonismo das lutas necessárias para pressionar tanto o poder estatal quanto os demais atores sociais, buscando ampliar as conquistas por melhores condições de trabalho e de vida da sociedade.

\section{REFERÊNCIAS}

ANGNES, Cláudia; BUFFON, Marciano; MORIGI, Valdir José. A evolução do papel do Estado na promoção dos direitos sociais - do Estado liberal ao pós-neoliberal. Revista de Direito Social, Sapucaia do Sul, v. 10, n. 40, p. 83106, out./dez. 2010.

BERCOVICI, Gilberto. A crise e a atualidade do Estado social para a periferia do capitalismo. Estudos no século XX, Separatas, n. 13, p. 129-144, 2013. Disponível em: https://digitalis-dsp.uc.pt/bitstream/10316.2/36801/1/A\%20 Crise\%20e\%20a\%20Atualidade\%20do\%20Estado.pdf

BOITO JUNIOR, Armando. A crise do sindicalismo. In: SANTANA, Marco Aurélio; RAMALHO, José Ricardo (org.). Além da fábrica. São Paulo: Boitempo Editorial, 2003. p. 319-333.

BONAVIDES, Paulo. Curso de direito constitucional. 31. ed. São Paulo: Malheiros Ed., 2016.

CANOTILHO, J. J. Gomes. O direito constitucional como ciência de direção: o núcleo essencial de prestações sociais ou a localização incerta da socialidade (contributo para a reabilitação a força normativa da "Constituição Social"). In: CANOTILHO, J. J. Gomes; CORREIA, Marcus Orione Gonçalves (org.). Direitos fundamentais sociais. São Paulo: Saraiva, 2010. p. 11-31.

CHEVALLIER, Jacques. O Estado pós-moderno. Trad. Marçal Justen Filho. Belo Horizonte: Fórum, 2009.

COGGIOLA, Osvaldo. A primeira internacional operária e comuna de Paris. Revista Aurora, a. 5, n. 8, p. 165-183, ago. 2011.

COMPARATO, Fabio Konder. A afirmação histórica dos direitos humanos. 6. ed. rev. e atual. São Paulo: Saraiva, 2008.

DALLARI, Dalmo de Abreu. Elementos de teoria geral do Estado. 24. ed. São Paulo: Saraiva, 2003.

DELGADO, Mauricio Godinho. Direito coletivo do trabalho. 7. ed. rev. atual. e ampl. São Paulo: LTr, 2017.

DELGADO, Mauricio Godinho; PORTO, Lorena Vasconcelos. O Estado de bem-estar social no capitalismo contemporâneo. Revista de Direito do Trabalho, São Paulo, v. 33, n. 128, p. 155-164, out./dez. 2007.

EBERT, Paulo Roberto Lemgruber. Sindicato mais representativo e mutação constitucional: uma proposta de releitura do art. 8으, II, da Constituição Federal. São Paulo: LTr, 2007.

ERMIDA URIARTE, Oscar. Intervenção e autonomia no direito coletivo do trabalho. Tradução: Kelly Karoline Bepe Fernandes e Sandro Lunard Nicoladeli. In: NICOLADELI, Sandro Lunard; PASSOS, André Franco de Oliveira; FRIEDRICH, Tatyana Scheila (org.). O direito coletivo, a liberdade sindical e as normas internacionais: o direito coletivo na OIT: normas, jurisprudência e reflexões sobre a normatividade protetiva da liberdade sindical. São Paulo: LTr, 2013. p. 11-19. V. 1.

ERMIDA URIARTE, Oscar. Sindicatos en libertad sindical. Montevideo: Fundación de Cultura Universitaria, 1985. ESPING-ANDERSEN, Gosta. The three worlds of welfare capitalism. Princeton: Princeton University Press, 1998.

FARIA, Carlos Aurélio Pimenta de. Uma genealogia das teorias e tipologias do Estado de bem-estar social. In: DELGADO, Maurício Godinho; PORTO, Lorena Vasconcelos (org.). O Estado de bem-estar social no século XXI. São Paulo: LTr, 2007. p. 31-87.

FELICIANO, Guilherme Guimarães. Por um processo realmente efetivo: tutela processual de direitos humanos fundamentais e inflexões no "due process of law". São Paulo: LTr, 2016.

FELICIANO, Guilherme Guimarães. Curso crítico de direito do trabalho: teoria geral do direito do trabalho. São Paulo: Saraiva, 2013.

GÓMEZ ISAZA, María Cristina. La historia del Estado social de derecho. Estudios de Derecho, Medellin, v. 63, n. 141, p. 73-99, abr. 2006.

KINDLEBERGER, Charles. Economic development. In: MAGANO, Octavio Bueno. Manual de direito do trabalho: direito coletivo do trabalho. 3. ed. rev. e atual. São Paulo: LTr, 1993. V. 3. 
LOUREIRO, João Carlos. Adeus ao Estado social? O insustentável peso do não ter. Boletim da Faculdade de Direito da Universidade de Coimbra, Coimbra, v. 83, p. 99-182, 2007.

MAGANO, Octavio Bueno. Manual de direito do trabalho: direito coletivo do trabalho. 3. ed. rev. e atual. São Paulo: LTr, 1993. V. 3.

MIRANDA, Jorge. Os novos paradigmas do Estado social. Revista Brasileira de Direito Comparado, Rio de Janeiro, n. 40-41, p. 13-27, jan./dez. 2011.

MIRANDA, Jorge. Estado social e direitos fundamentais. Revista da Faculdade de Direito da Fundação Armando Álvares Penteado, São Paulo, v. 2, n. 2, p. 7-19, 2003-2004.

NUNES, António José Avelãs. A crise atual do capitalismo. São Paulo: Ed. Revista dos Tribunais, 2012.

NUNES, António José Avelãs. O Estado capitalista e as suas máscaras. 2. ed. Rio de Janeiro: Lumen Juris, 2013.

OIT. Organización Internacional del Trabajo. Conferencia Internacional del Trabajo, 95a Reunión, 2006. Informe V (1). La relación de trabajo. Ginebra: Oficina Internacional del Trabajo, 2006. p. 80-88.

PORTO, Pedro Rui da Fontoura. Direitos fundamentais sociais: considerações acerca da legitimidade política e processual do Ministério Público e do sistema de justiça para sua tutela. Porto Alegre: Livraria do Advogado, 2006.

RODRIGUEZ, José Rodrigo. Dogmática da liberdade sindical: direito, política, globalização. Rio de Janeiro: Renovar, 2003.

ROMITA, Arion Sayão. Organização sindical, Justiça do Trabalho, direito à greve na Constituição. Rio de Janeiro: Edições Trabalhistas, 1987.

SANTOS, Ronaldo Lima dos. Aspectos da atuação do Ministério Público do Trabalho em matéria sindical (EC. $n$. 45/2004) à luz dos princípios do Comitê de Liberdade Sindical da OIT. Revista LTr, São Paulo, ano 70, n. 11, p. 1.338-1.348, nov. 2006.

SILVA, José Afonso da. Curso de direito constitucional positivo. 38. ed. rev. e atual. São Paulo: Malheiros Ed., 2015.

TORRES, Ricardo Lobo. O direito ao mínimo existencial. Rio de Janeiro: Renovar, 2009.

15 PAÍSES COM MAIS TRABALHADORES AUTÔNOMOS. Forbes, 4 jul. 2008. Disponível em: http://forbes.uol.com. br/carreira/2018/07/15-paises-com-mais-trabalhadores-autonomos/. Acesso em: 11 fev. 2020. 